CLINICAL STUDY

\title{
Modifications of bone material properties in postmenopausal osteoporotic women long-term treated with alendronate
}

\author{
Yohann Bala $^{1,2}$, Delphine Farlay ${ }^{1,2}$, Roland D Chapurlat ${ }^{1,2}$ and Georges Boivin ${ }^{1,2}$ \\ ${ }^{1}$ INSERM, UMR1033, F-69008 Lyon, France and ${ }^{2}$ Université de Lyon, F-69008 Lyon, France \\ (Correspondence should be addressed to Y Bala at INSERM, UMR 1033, Equipe Qualité Osseuse et Marqueurs Biologiques, Faculté de Médecine Lyon Est, \\ Université de Lyon, Claude Bernard (Domaine Laennec), 69372 Lyon Cedex 08, France; Email: yohannbala@gmail.com)
}

\begin{abstract}
Objective: Given recent concern about long-term safety of bisphosphonate (BP) therapy, the effects of long-term alendronate (ALN) therapy on intrinsic bone properties were studied among postmenopausal osteoporotic (PMOP) women.

Design and methods: Transiliac bone biopsies were obtained from 32 outpatient clinic PMOP women treated with oral ALN for $6.4 \pm 2.0$ years. Variables reflecting bone mineralization were measured both at tissue level using quantitative microradiography and at crystal level by Fourier transform infrared microspectroscopy. Bone microhardness was investigated by Vickers indentation tests. Results were compared with those from 22 age-matched untreated PMOP women.

Results: Long-term treatment with ALN was associated with a $84 \%(P<0.001)$ lower remodeling activity compared with untreated PMOP women, leading to an increased degree of mineralization in both cortical and trabecular bone $(+9$ and $+6 \%$, respectively, $P<0.05)$. Despite a more mature and more mineralized bone matrix, after treatment, cortical and trabecular microhardness and crystallinity were lower than that measured in untreated patients. None of the variables reflecting material properties were significantly correlated to the duration of the treatment.

Conclusion: Increased degree of mineralization associated with lower crystallinity and microhardness in ALN long-term-treated PMOP women suggests that ALN could alter the quality of bone matrix. The study also suggested that after 3 years of treatment, the changes in material properties are not dependent on the duration of the treatment. Further studies are requested to assess the short-term $(<3$ years) effects of BPs on bone intrinsic properties.
\end{abstract}

European Journal of Endocrinology 165 647-655

\section{Introduction}

Bisphosphonates (BPs) are widely used in the treatment of postmenopausal osteoporosis (PMOP) as effective anti-resorptive agents. They reduce the risk of vertebral (1) and non-vertebral fractures (2). This effect was associated with an increase in bone mineral density (BMD), but BMD moderately reduces in fracture risk (3). The effects of BPs on bone tissue properties remain unclear. Bone strength is explained by numerous determinants reflecting both extrinsic (bone mass and microarchitecture) and intrinsic (mineral and collagen quality, mineralization and accumulation of microdamage) properties of bone matrix (4-6). Bone quality also depends on bone remodeling activity. The decrease in bone remodeling activity prolongs the lifetime of bone structural units (BSUs), so it increases the duration of secondary mineralization, leading to an increase in the degree of mineralization of bone (DMB), which is a major determinant of bone strength $(4,7)$. Thus, after 3 years of treatment with alendronate (ALN) (7-9) or risedronate (10), a significant increase in the DMB has been observed, often associated with a decrease in the heterogeneity of the mineralization.

It has been suggested that oversuppression of both targeted and non-targeted bone remodeling could impair bone quality. In a canine model, the prolonged use of high doses of BPs led to an accumulation of bone microdamage with a decrease in some of the bone mechanical variables $(11,12)$. In this animal model, alterations in collagen cross-linking and isomerization have also been described (13). However, an increase in bone microdamage in osteoporotic patients receiving oral BPs has not yet been established (14). To date, only few data on the effect of long-term BP therapies on bone intrinsic properties have been reported. The cases of atypical subtrochanteric femoral fractures in OP patients receiving long-term therapy with ALN have been reported $(15,16)$. In some instances, prolonged BP therapies were also associated with rare cases of adynamic bone and delayed fracture healing (17). BPs may also impair both cortical and cancellous bone elasticity during therapies shorter or longer than 3 years (18). The cases of osteonecrosis of the jaw 
have been described in patients receiving oral BP therapies (19) but essentially in the context of high cumulative doses for the treatment of multiple myeloma or bone metastasis.

At the bone tissue level, the analysis of iliac crest biopsies from a subgroup of the FIT long-term extension (FLEX) trial (comparing 10 years ALN and 5 years ALN +5 years placebo groups) showed no accumulation of osteoid and no impaired mineralization. After 10 years of ALN therapy, the mineralization level was not greater than that after 5 years, and its heterogeneity was not decreased (20).

This study aims to highlight the effects of long-term ALN therapies on intrinsic determinants of bone quality. The DMB, mineral characteristics, and the Vickers microhardness $(\mathrm{Hv})$ were assessed in transiliac bone biopsies from 32 outpatient clinic PMOP women on long-term ALN therapy (21). In a cross-sectional study, we have compared these women with untreated PMOP women.

\section{Materials and methods}

\section{Subjects}

We have studied 32 outpatient clinic PMOP women treated long-term with ALN (ALN $\mathrm{AT}_{\mathrm{LT}}, 10 \mathrm{mg}$ daily or $70 \mathrm{mg}$ weekly). The subject disposition and techniques are shown in Fig. 1. In this group, 18 patients sustained at least one osteoporotic fracture (three at the hip and 15 at the spine) before the treatment. Twenty-four patients received their medication for at least 5 years, and the mean duration of BPs therapy was $6.4 \pm 2.0$ years (mean \pm s.D.; range: $3-10$ years). Their mean age was $70.4 \pm 8.6$ years, at least 5 years postmenopause, and their mean bone volume over tissue volume $(\mathrm{BV} / \mathrm{TV})$ was $13.40 \pm 4.5 \%$. Exclusion criteria were the presence of metabolic bone diseases other than PMOP; the use of any medication other than BPs likely to interfere with skeletal metabolism within the past 6 months; uncontrolled hyperthyroidism; alcohol or drug abuse, current or within the past 5 years; allergy to tetracycline or novocain; hip anatomy preventing from transiliac bone biopsy or absorptiometry scan; and previous bilateral transiliac bone biopsies (21).

Results were compared with those obtained in a group of 22 iliac bone samples taken from untreated PMOP women (mean age $=69.4 \pm 5.5$ years, mean $\mathrm{BV} / \mathrm{TV}=17.2 \pm 3.5 \%$ ) with either a BMD at least -2.5 S.D. below the young adult mean or at least two radiographically apparent moderate vertebral fractures ( $>25 \%$ vertebral height loss) (22).

\section{Bone samples}

Transiliac bone biopsies were performed after patients were double-labeled with demethylchlortetracycline

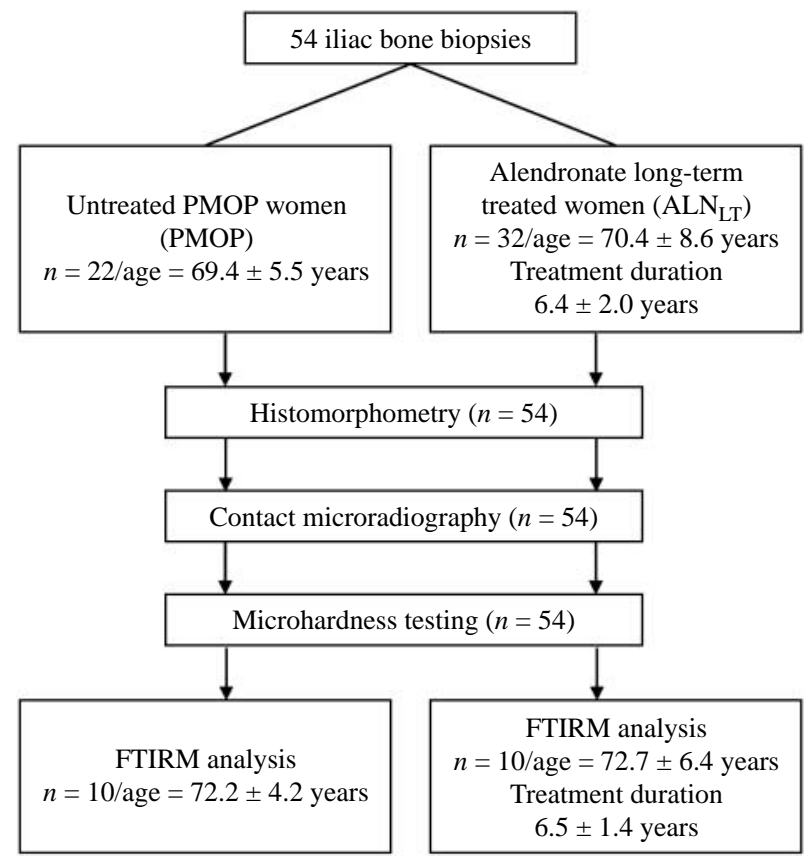

Figure 1 Description of the groups involved in the study of the effects of alendronate long-term treatment in material properties (Fourier transform infrared microspectroscopy (FTIRM)).

(600 mg/day, 2 days on, 10 days off, 2 days on). The Samples were fixed, dehydrated, and then embedded in methyl methacrylate (MMA). For quantitative microradiography, thick sections (about $150 \mu \mathrm{m}$ ) were cut from embedded bone samples using a precision diamond wire saw (Well, Escil, Chassieu, France), progressively ground to a thickness of $100 \pm 1 \mu \mathrm{m}$, and polished with an alumina suspension $(1 \mu \mathrm{m})$. For microhardness tests, embedded blocks were surfaced and polished using a diamond suspension $(0.25 \mu \mathrm{m})$. On the residual blocks, 2-5 $\mu \mathrm{m}$-thick sections were cut using a Polycut E microtome (Leica, Wetzlar, Germany) after the grinding of indented surface. The cutting plane perpendicular to the Haversian canals of cortical bone was preferred.

\section{Assessment of bone remodeling by histomorphometry}

Bone histomorphometry was performed on cancellous bone only, on $8 \mu \mathrm{m}$-thick unstained sections. Parameters were expressed according to the recommended American Society for Bone and Mineral Research (ASBMR) nomenclature (23): mineral apposition rate (MAR in $\mu \mathrm{m} /$ day) and mineralizing surface/bone surface (MS/BS in \%) was calculated as one-half single + double-labeled surfaces. Bone formation rate/BS (BFR/BS in $\mu \mathrm{m}^{3} / \mu \mathrm{m}^{2}$ per day) was calculated as $((\mathrm{MS} / \mathrm{BS}) \times \mathrm{MAR})$. The activation frequency (Ac.F defined by the number of new basic multicellular units created per unit of time expressed in \#/years) was calculated as $((\mathrm{BFR} /$ wall thickness $(\mathrm{W} . \mathrm{Th})) \times 365)$. 
The W.Th (in $\mu \mathrm{m}$ ), representing the endproduct of the osteoblastic activity in a remodeling site, was measured under polarized light on Solochrome cyanine R-stained $8 \mu \mathrm{m}$-thick sections.

\section{Quantitative microradiography}

Contact microradiography of $100 \mu$ m-thick bone sections was performed using an x-ray diffraction unit PW 1830/40 (Philips, Limeil Brévannes, France) (24). The nickel-filtered copper $\mathrm{K} \alpha$ radiation was used under $25 \mathrm{kV}$ and $25 \mathrm{~mA}$. Both bone sample and an aluminum standard X-ray absorption were recorded on a highresolution film exposed for $20 \mathrm{~min}$ (Geola, Slavich International Wholesale Office, Vilnius, Lithuania). Acquisition of microradiographs was performed using a digital camera (resolution: $800 \times 600$ ). After calibration using an aluminum reference, the threshold for measured regions of bone tissue was determined, prior to gray-level segmentation. Finally, gray-level values were converted into DMB values (in g mineral/ $\left.\mathrm{cm}^{3}\right)$ for each pixel $(5.64 \mu \mathrm{m}$ a side). The main reported variables were $\mathrm{DMB}$ and the index of heterogeneity of the distribution of DMB values, calculated as the full width at half-maximum (FWHM) on the individual DMB curves (heterogeneity index (HI) in $\mathrm{g} / \mathrm{cm}^{3}$ ). These variables were separately measured on cortical and cancellous bone.

\section{Fourier transform infrared microspectroscopy}

Fourier transform infrared microspectroscopy (FTIRM) was performed on 2-5 $\mu$ m-thick sections to measure mineral characteristics at the crystal level. Infrared spectra were obtained from a total area of $35 \times 35 \mu \mathrm{m}$ (25). Spectra were obtained using a Spectrum 100 spectrometer equipped with an Auto-IMAGE microscope (Perkin-Elmer, Shelton, CT, USA). Each spectrum corresponded to 150 cumulated scans. The contributions of air and MMA were subtracted from the individual spectra, and a baseline correction was done (Fig. 2). The spectra were then curve-fitted using GRAMS/AI Software (Thermo galactic, Salem, NH, USA) to analyze the peaks $\nu_{4} \mathrm{PO}_{4}\left(500-650 \mathrm{~cm}^{-1}\right)$ and $\nu_{1} \nu_{3} \mathrm{PO}_{4}\left(900-1200 \mathrm{~cm}^{-1}\right)$. The mineral crystallinity index was inversely correlated to the FWHM of the $604 \mathrm{~cm}^{-1}$ band in the $\nu_{4} \mathrm{PO}_{4}$ domain. Mineral crystallinity index corresponded to the crystal size/perfection. The mineral maturity reflecting transformation of immature precursors of the hydrated layer into a mature apatite was calculated as the area ratio $1030 \mathrm{~cm}^{-1}$ over $1110 \mathrm{~cm}^{-1}\left(\nu_{3} \mathrm{PO}_{4}\right)$. Spectra were obtained from 720 cortical and cancellous BSUs (osteons, packets, and interstitial bone) from ten untreated PMOP and ten $\mathrm{ALN}_{\mathrm{LT}}$ samples to fit with the initial population distribution as much as possible (Fig. 1).
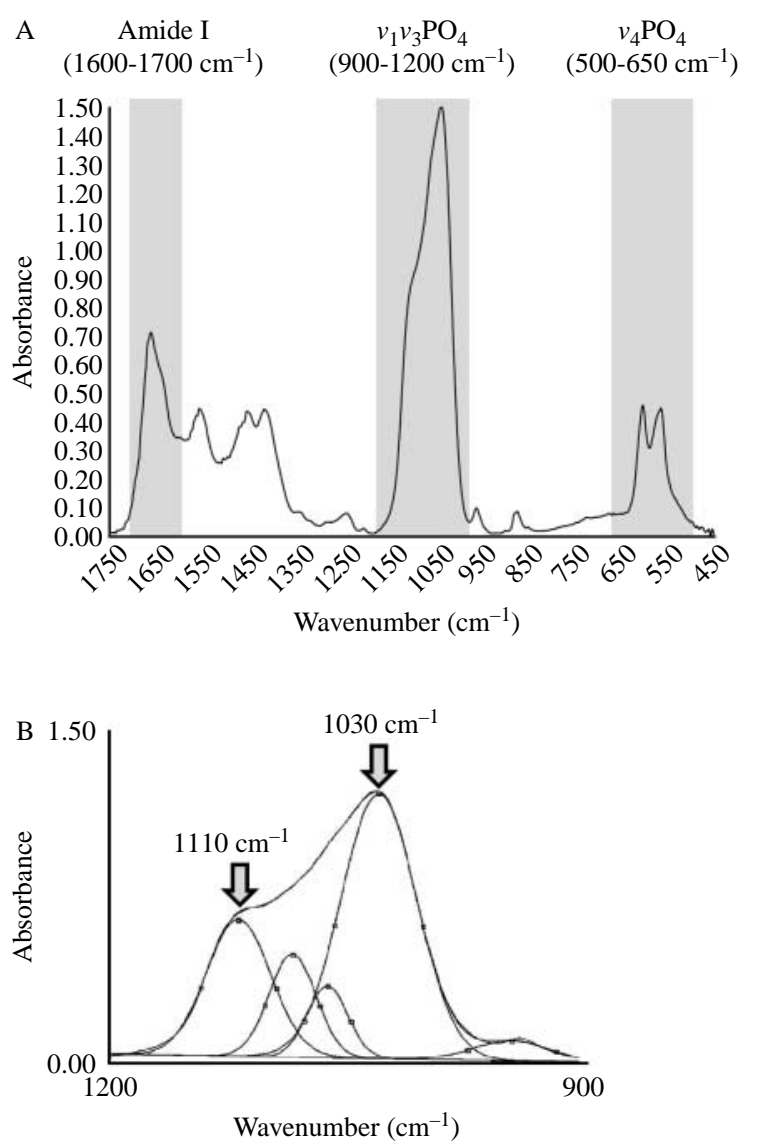

Figure 2 Typical infrared spectra obtained on bone with the analyzed vibration domains $(\mathrm{A})$ and curve-fitting of the $\nu_{1} \nu_{3} \mathrm{PO}_{4}$ domain allowing the calculation of the mineral maturity as the area ratio of $1030 \mathrm{~cm}^{-1}$ over the $1110 \mathrm{~cm}^{-1}$ peaks (B).

\section{Measurement of microhardness}

Mean bone tissue microhardness was measured using a Micromet 5104 tester (Buehler, Lake Bluff, IL, USA) (24) equipped with a Vickers indenter corresponding to a square-based diamond indenter. A load of $25 \mathrm{~g}$ applied for $10 \mathrm{~s}$ was used. Hv, defined as the mean pressure the material will support under load ( $\mathrm{Hv}$ in $\mathrm{kg} / \mathrm{mm}^{2}$ ), was computed from $\mathrm{Hv}=1854.4 \times P / d^{2}$, where $P$ is the test load in grams and $d$ is the mean length of both the diagonals in $\mu \mathrm{m}$. A total of 60 random impressions were analyzed for each bone sample, corresponding to 40 measurements in cortical bone and 20 measurements in cancellous bone. The data obtained for each bone sample were expressed as a mean both in cortical and cancellous bone.

\section{Statistical analysis}

Analyses were performed using SPSS v16.0 (SPSS, Inc., Chicago, IL, USA) with an alpha risk level defined at 5\%. Results were reported as mean \pm s.D. The distribution 
Table 1 Dynamic histomorphometric variables measured in untreated postmenopausal women (PMOP) and in PMOP women long-term treated with oral alendronate $\left(A L N_{L T}\right)$.

\begin{tabular}{lcc}
\hline & PMOP & ALN \\
\hline MAR $(\mu \mathrm{m} /$ day) & $0.641(0.096)$ & $0.718(0.148)$ \\
MS/BS $(\%)$ & $7.408(4.652)$ & $0.435(0.615)^{*}$ \\
BFR/BS $\left(\mu \mathrm{m}^{3} / \mu \mathrm{m}^{2}\right.$ per day) & $0.048(0.034)$ & $0.004(0.005)^{*}$ \\
Ac.F (\#/year) & $0.396(0.255)$ & $0.063(0.066)^{*}$ \\
\hline
\end{tabular}

${ }^{\star} P<0.0001$ versus $\mathrm{PMOP}$.

of the degree of mineralization and microhardness was tested with the Shapiro-Wilk procedure. Nonparametric tests were used because the distributions were not normal. Means were compared using MannWhitney's $U$ test in case of significant results previously obtained using Friedman's test. Correlations were tested using Spearman's rho test $\left(r^{\prime}\right)$. FTIRM analyses were performed on subsets of ten samples per analyzed group. Owing to the small number of individuals, medians were tested. Mood's median test was used for the null hypothesis $H_{0}$ : medians of the populations from which two samples are drawn are identical.

\section{Results}

\section{Bone remodeling activity}

Even after multiple sectioning, no fluorescent labels were found in seven samples. Those samples were not taken into account in the analysis. Using 2D histomorphometry, the MAR was normal and not significantly different between the groups (Table 1). The MS/BS, BFR/BS, and Ac.F were significantly lower in $\mathrm{ALN}_{\text {LT }}$ group compared with the PMOP group (Table 1). When data were pooled for ALN $\mathrm{LTT}_{\mathrm{LT}}$ and PMOP groups, DMB and HI were significantly correlated with the Ac.F, with $r^{\prime}=-0.37, P=0.02$, and $r^{\prime}=0.35, P=0.02$ respectively (Fig. 3). Hv was not significantly correlated with the Ac.F ( $r^{\prime}=0.23$, NS).

\section{DMB and its heterogeneity}

The DMB measured in cancellous bone was significantly greater after long-term ALN treatment compared with untreated PMOP women (Table 2). The cancellous HI was significantly lower after ALN treatment versus PMOP $\left(-18 \%, P=0.043 \operatorname{ALN}_{\mathrm{LT}}\right.$; Table 2). In cortical bone, the DMB also increased in ALN-treated women (Table 2), whereas the HI was not as low as observed in cancellous bone. When measured in cortical bone, neither DMB nor HI was significantly correlated with the duration of the treatment $\left(r^{\prime}=0.15\right.$ and -0.14 NS respectively). This was also true in cancellous bone $\left(r^{\prime}=0.21\right.$ and $\left.0.10, \mathrm{NS}\right)$.

\section{Mineral characteristics measured by FTIRM}

In cortical bone, mineral maturity was significantly greater in the $\mathrm{ALN}_{\mathrm{LT}}$ group than in the PMOP group, both in osteonal and interstitial bone $(+14$ and $+16 \%$, $P<0.05$, respectively; Table 3$)$. These results were systematically observed in cancellous bone $(+6$ and $+7 \%, P<0.05$, for bone packets and interstitial bone respectively). In each analyzed bone compartment of treated bone, FWHM of the peak at $604 \mathrm{~cm}^{-1}$ was significantly higher (from 2 to $4 \%, P<0.05$ ) than that measured in untreated women (Table 3). This indicated that in long-term-treated patients, crystallinity index was significantly lower than that in untreated PMOP women. Mean $\mathrm{Hv}$ (cortical+cancellous bone) was significantly and inversely correlated $\left(r^{\prime}=-0.50\right.$, $P=0.03$ ) with the mean FWHM $604 \mathrm{~cm}^{-1}$, i.e. mean of all measurements performed per sample (Fig. 4). Thus, microhardness increases with the size/perfection of crystals at tissue level.

\section{Bone microhardness}

The Hv measured in the $A_{L N}$ LrT group (Table 2) was significantly lower than that in the PMOP women. This result was observed both in cancellous $(-7.8 \%$, $P=0.0006)$ and cortical $(-7.5 \%, P=0.0004)$ bone.
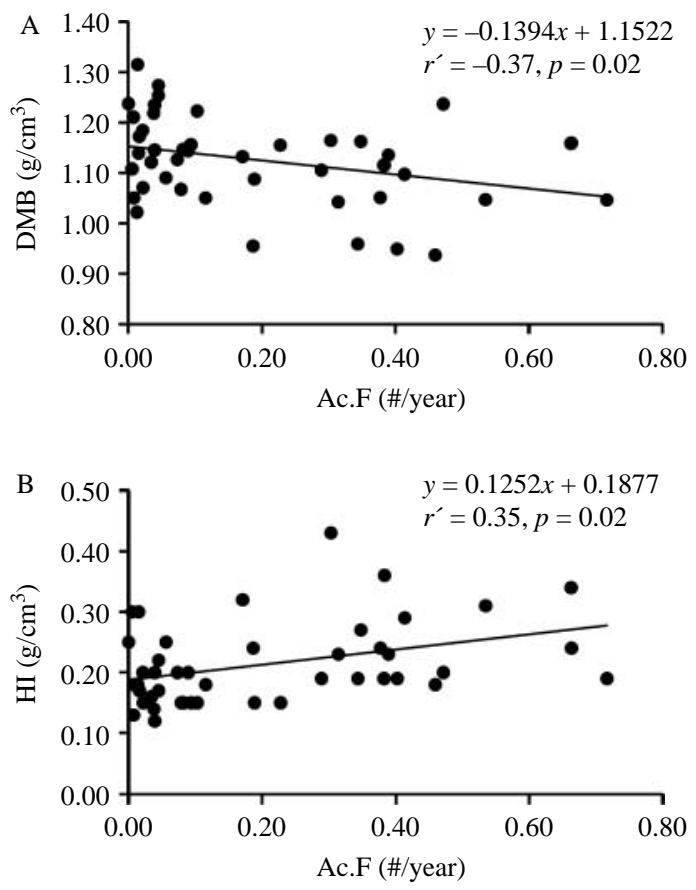

Figure 3 Significant correlations were observed between the activity of bone remodeling assessed by 2D histomorphometry (activation frequency (Ac.F)) and degree of mineralization of bone $(\mathrm{DMB}, \mathrm{A})$ and its heterogeneity index $(\mathrm{HI}, \mathrm{B})$ obtained using quantitative microradiography among the whole population. 
Table 2 DMB, HI, and microhardness (Hv) measured in iliac bone tissue from PMOP and ALN $N_{L T}$. Values are reported as mean (S.D.).

\begin{tabular}{llclllll}
\hline & \multicolumn{3}{c}{ Cortical bone } & & \multicolumn{3}{c}{ Cancellous bone } \\
\cline { 2 - 3 } \cline { 7 - 8 } Subjects & $\mathrm{DMB}\left(\mathrm{g} / \mathrm{cm}^{3}\right)$ & $\mathrm{HI}\left(\mathrm{g} / \mathrm{cm}^{3}\right)$ & $\mathrm{Hv}\left(\mathrm{kg} / \mathrm{mm}^{2}\right)$ & & $\mathrm{DMB}\left(\mathrm{g} / \mathrm{cm}^{3}\right)$ & $\mathrm{HI}\left(\mathrm{g} / \mathrm{cm}^{3}\right)$ & $\mathrm{Hv}\left(\mathrm{kg} / \mathrm{mm}^{2}\right)$ \\
\hline PMOP & $1.033(0.082)$ & $0.249(0.065)$ & $48.773(2.657)$ & & $1.077(0.081)$ & $0.244(0.070)$ & $49.302(2.538)$ \\
ALN $_{\mathrm{LT}}$ & $1.123(0.069)^{*}$ & $0.211(0.058)^{\dagger}$ & $45.139(4.211)^{*}$ & & $1.140(0.062)^{*}$ & $0.200(0.050)^{*}$ & $45.435(4.651)^{*}$ \\
\hline
\end{tabular}

${ }^{*} P<0.05$ and ${ }^{\dagger} P=0.07$ versus $P M O P$.

$\mathrm{Hv}$ values were not significantly correlated with the duration of the treatment period $\left(r^{\prime}=-0.21\right.$ and -0.12 , NS, for cancellous and cortical bone respectively).

\section{Discussion}

This study is the first report of the effects on bone mineralization, mineral characteristics, and microhardness of a long-term treatment with ALN in outpatient clinic PMOP women. The DMB measured in PMOP women treated for 6.4 years with ALN was significantly greater than that measured in untreated PMOP women in cancellous and cortical bone. This study also showed significant correlations between variables of bone remodeling measured by 2D histomorphometry and the DMB and its HI, as observed with other methods (26). This correlation can be explained by the fact that the increase in DMB was linked to a profound decrease in remodeling activity (e.g. Ac.F was up to $80 \%$ lesser in $\mathrm{ALN}_{\mathrm{LT}}$ group compared with untreated PMOP women). This was confirmed by the decrease in HI. The increase in DMB observed during ALN treatment is due to a higher proportion of bone matrix with greater mineralization. That is, it had a greater duration of secondary mineralization due to the depressed remodeling activity (7-9). This phenomenon has also been described with several other inhibitors of bone resorption used in the treatment of PMOP such as other BPs and selective estrogen receptor modulators $(22,26)$. Interestingly, changes in microhardness were not correlated with Ac.F, as opposed to the increase in mineralization, suggesting that the decrease in hardness is independent of the slowdown in remodeling activity.
Compared with data previously published following a 3-year treatment (7), even if long-term ALN treatment maintained DMB at a higher level than untreated PMOP women, it seemed that it was not time dependent. Indeed, after 3 years of ALN therapy, the reported mean DMB values were $1.19 \pm 0.016 \mathrm{~g} / \mathrm{cm}^{3}$ in both cortical and trabecular bone while our ALN $\mathrm{LT}_{\mathrm{LT}}$ group presented 6 and $4 \%$ lower values in cortical and trabecular bone respectively. Results concerning BMD and biochemical markers of bone remodeling in the FLEX trial showed that a 10-year treatment with ALN (10 mg/day) had been related to a higher BMD in total hip and other skeletal sites and lower levels of bone turnover markers $(27,28)$. Moreover, bone mineralization, measured by quantitative backscattered electron imaging, did not significantly differ between the 5-year ALN group followed by 5 -year placebo and the 10-year ALN groups (20). This suggested no progressive increase in the degree of mineralization with continued therapy and the reaching of a new equilibrium situation. This is in accordance with a previous study showing that between 5 and 10 years of treatment with ALN (FLEX trial), the increase in the degree of mineralization plateaued while heterogeneity increased (20). This is consistent with a rapid decrease in biochemical markers of bone turnover observed during the first months of treatment and the decrease in mineralization heterogeneity up to 5 years of therapy $(9,29,30)$. Thereafter, levels of biochemical markers of bone turnover remained lower at the same level over 10 years of treatment, i.e. the continuation of the therapy was not associated with a more marked inhibition of bone turnover (28). Similar trends have also been reported with risedronate in a triple biopsy study (at baseline and after 3 and 5 years of treatment). Risedronate was

Table 3 Mineral characteristics measured by FTIRM measured in cortical and cancellous bone. Crystallinity index is inversely proportional to the FWHM of the peak at $604 \mathrm{~cm}^{-1}$. Values are reported as median (range).

\begin{tabular}{|c|c|c|c|c|}
\hline \multirow[b]{2}{*}{ FTIRM variables } & \multicolumn{2}{|c|}{ Cortical bone } & \multicolumn{2}{|c|}{ Cancellous bone } \\
\hline & Osteonal bone & Interstitial bone & Bone packets & Interstitial bone \\
\hline \multicolumn{5}{|l|}{ Mineral maturity } \\
\hline PMOP & $1.618(1.384-2.027)$ & $1.891(1.744-2.127)$ & $1.559(1.252-1.716)$ & $1.674(1.508-2.053)$ \\
\hline $\begin{array}{l}\text { ALN }{ }_{L T} \\
\text { FWHM } 604 \mathrm{~cm}^{-1}\end{array}$ & $1.852(1.646-1.986)^{\star}$ & $2.189(1.942-2.331)^{*}$ & $1.655(1.265-1.887)^{*}$ & $1.795(1.469-2.271)^{\star}$ \\
\hline PMOP & $25.391(23.596-26.889)$ & 24.422 (23.695-26.343) & 25.197 (24.597-26.296) & $24.422(23.164-25.496)$ \\
\hline$A L N_{L T}$ & $25.864(25.113-26.929)^{*}$ & $25.296(24.779-26.019)^{*}$ & $25.790(24.282-27.314)^{\star}$ & $25.329(24.161-26.181)^{*}$ \\
\hline
\end{tabular}

${ }^{*} P<0.05$ versus PMOP. 


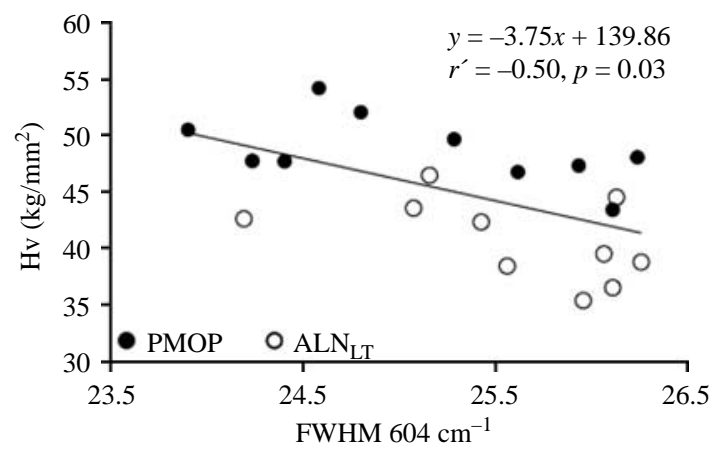

Figure 4 Mean microhardness (Hv pooled for cortical and cancellous bone) was significantly and inversely correlated with the FWHM of the peak at $604 \mathrm{~cm}^{-1}$. As the FWHM $604 \mathrm{~cm}^{-1}$ is inversely proportional to the crystallinity index, this correlation implies that $\mathrm{Hv}$ increases at tissue level with the size/perfection of crystals.

associated with a significant increase in mineralization after 3 years toward premenopausal values and no further increase after 5 years of treatment $(10,31)$. Taken together, these results are consistent with the fact that this study detected no association between duration of treatment and the outcome variables.

Regarding the upper tails of histograms of DMB values, there were no signs of hypermineralization compared with untreated women from a separate study ( $n=30$, mean age \pm s.D. (range): $49 \pm 21$ (20-93) years) $(24,32)$. Indeed, the highest represented DMB class was $1.45-1.50 \mathrm{~g} / \mathrm{cm}^{3}$ in the two groups and their frequencies of observation were 0.1 and $0.003 \%$ in $\mathrm{ALN}_{\mathrm{LT}}$ and untreated control women respectively. Furthermore, mean DMB and HI values measured in $\mathrm{ALN}_{\mathrm{LT}}$ were in the range of values obtained from untreated control women $(24,32)$. The increase in mean DMB observed after a long-term ALN treatment was due to a highest frequency of upper values of DMB.

A positive correlation between hardness and bone mineralization has previously been observed at both the tissue and the BSU levels (24). Thus, the lower hardness values in cortical and cancellous bone of $\mathrm{ALN}_{\mathrm{LT}}$ group compared with untreated PMOP group was an unexpected result. DMB and hardness have also been measured in a small group of PMOP women long-term treated with oral risedronate $(n=13$, age $=63 \pm 10$ years, duration of the treatment $=5 \pm 1$ years). In this group, DMB, HI, and $\mathrm{Hv}$ measured for total bone (cortical+cancellous) were $1.101 \pm 0.061,0.196$ $\pm 0.063 \mathrm{~g} / \mathrm{cm}^{3}$, and $46.522 \pm 2.253 \mathrm{~kg} / \mathrm{mm}^{2}$ respectively. Values were not different from those obtained in $\mathrm{ALN}_{\mathrm{LT}}$ patients, suggesting that the decrease in hardness is not specific to ALN (33). However, this group of biopsies was no longer available for FTIRM analyses. Thus, if the decrease in hardness seems to be not exclusive to ALN, this study cannot raise the potential differences in the mechanism leading to a lower hardness between ALN and risedronate.
If the increase in DMB and its homogenization after BPs are now well documented, there is a lack of data concerning hardness or elastic modulus measured at the tissue level after either a short- or a long-term administration with either ALN or other BPs. These data were obtained exclusively in animal models. In ovariectomized (OVX) rats treated with pamidronate $(0.6 \mathrm{mg} / \mathrm{kg}, 5$ day per month) for 16 weeks, a significant decrease in the indentation modulus was found, while hardness was not changed compared with OVX receiving the vehicle (34). In dogs receiving ALN ( $6 \mathrm{mg}$ daily) for 23 weeks, there was no modification of microhardness (35). Conversely, during a prolonged treatment of 1 year with ALN $(0.2 \mathrm{mg} / \mathrm{kg}$ per day), canine cancellous vertebral bone was harder than that in control group, but the modulus was not changed (36). Our observation could be explained by changes in tissue mineral quality.

In this study, we found a significant increase in mineral maturity and a decrease in crystallinity. As recently published, the mineral crystallinity index (crystals size/perfection) has to be separated from the mineral maturity (progressive transformation of non-apatitic into poorly then crystallized apatite) $(25,37,38)$. Mineral maturity is related to the ratio between apatitic over nonapatitic phosphates and gives indication on the evolution of the maturation of phosphate environments in bone mineral. Indeed, mineral maturity is strongly linked with the 'age' of the bone matrix. The mineral maturity measured on the $1030 / 1110 \mathrm{~cm}^{-1}$ ratio is comparable to the $1030 / 1020 \mathrm{~cm}^{-1}$ ratio used by other authors (8) and good correlations were observed between the two variables $\left(r^{\prime}=0.86, P<0.0001\right)(25)$. After 3 years of ALN, a slight but not significant increase in $1030 / 1020 \mathrm{~cm}^{-1}$ ratio was observed, showing a trend in the increase in age of bone mineral consistent with BP treatment (8). Consistently, after a long-term treatment with ALN, we also found an increase in $1030 / 1110 \mathrm{~cm}^{-1}$ ratio in agreement with the effect of BPs. The ratio $1030 / 1020 \mathrm{~cm}^{-1}$ has been called mineral maturity/ crystallinity due to the good correlation in normal bone with absolute crystallinity measured by X-ray diffraction. Crystallinity reflects both a combination of the relative sizes of the crystal as well as the extent to which the atoms in the lattice are ordered. We also found this correlation in normal bone between mineral maturity and crystallinity index. However, this was not always the case. For example, in skeletal fluorosis compared with normal bone, mineral exhibits a lower maturity (stimulation of osteoblasts by fluoride ions) and a higher crystallinity (substitution $\mathrm{OH}^{-}$by $\mathrm{F}^{-}$). It has been recently shown that the FWHM of $604 \mathrm{~cm}^{-1}$ band was a good indicator of the state of bone crystallinity (25).

In the current study, an impairment of crystallinity was observed after a long-term ALN treatment while the mineral maturity was higher than that in untreated PMOP women. This dissociation between crystallinity 
and the age of mineral has already been reported in women treated with zoledronate for 3 years (39). In the latter study, mineral apposition rate was significantly increased. Thus, for a bone of same age, crystals were younger in zoledronate than in placebo groups, explaining the lower crystallinity (39). Our study did not reveal any changes in mineralization apposition rate between PMOP and $\mathrm{ALN}_{\mathrm{LT}}$ groups, limiting this hypothesis in ALN case.

Vibrational spectroscopic methods do not allow to distinguish whether the perfection of the apatite crystalline domain and/or their size/strain were influenced by long-term ALN. Furthermore, the decrease in crystal size being unlikely, a decrease in mineral perfection (organization of atoms within apatite lattice), seems more probable and could be related to the adsorption of ALN on bone apatite. Some studies have suggested a direct implication of ALN in crystal structure changes. Indeed, from the observation that small differences in BP structure could lead to great changes in mineral affinity, it has been suggested that the 3D configuration of nitrogen containing BP and its spatial orientation may play an important role (40). This was evaluated using a 3D numerical model that simulated chemical links between BPs and apatite surfaces. This work showed that the P-C-P (common structure of BPs) bridge binds ALN to apatite on a Ca (Ca I site) but also that the nitrogen atom could create a $\mathrm{N}-\mathrm{H}-\mathrm{O}$ hydrogen bond with an $\mathrm{OH}$ coordinated to another Ca (Ca II site) (41). Such a binding in two sites related to Ca I and Ca II sites could directly influence apatite crystal properties as its perfection (40). Furthermore, the binding of ALN to apatite leads to modification of both the zeta potential and interfacial tension (42). The description of the shape and the kinetics of the growth of crystals are sensitive to the electric environment $(42,43)$. ALN is thus able to influence the crystallinity of apatite by various mechanisms.

While the strength of bone is highly related to the amount of mineral (4), there are published results showing that changes in microhardness might be induced by modifications of crystal properties such as its perfection. It has been shown in human femur that crystallinity measured by Raman spectroscopy explained $6.7-48.3 \%$ of the variability of monotonic mechanical properties and $11.3-63.5 \%$ in fatigue properties (44). Recently, we have also shown that during physiological mineralization of bone tissue, the kinetics of the mineral crystallinity index was slower than that of the mineral maturity or mineralization index, and microhardness (37). In the latter study, it was observed that during the mineralization of an osteon, microhardness was increased by $60 \%$ while the crystallinity was increased by $8 \%$. This could explain why in this study, a decrease of $8 \%$ in microhardness could be related to a change of only $2 \%$ in mineral crystallinity. These results allow to speculate that changes in crystallinity could explain, at least partially, the decrease in bone microhardness. This hypothesis is reinforced by the finding of a significant correlation between mean $\mathrm{Hv}$ and mean crystallinity index, showing that the higher mean crystal size/perfection is, harder is the bone tissue. However, this correlation has to be considered with cautions as the design of the methodologies did not allow to test this correlation directly in the same regions of interests.

The effect of ALN on mineral characteristics is probably only a part of the mechanism leading to a decrease in microhardness. This is supported in this study by the scatter plot showing the correlation between hardness and crystallinity. Indeed, the overlap of the values of crystallinity while the values of hardness were higher in the untreated group implied that the role of crystallinity in local mechanical properties is different between the groups. The differences might be explained by changes in organic matrix properties. The DMB explains about $60 \%$ of the variability of bone microhardness, the remaining being partially explained by the hardness inherent to organic matrix (24). In addition, many works have highlighted modifications of organic matrix associated with the use of BPs. In beagle dogs, high doses of both risedronate and ALN were followed by an alteration of the collagen crosslinking and isomerization, i.e. an index of collagen maturity (13). In human recently deposited bone matrix, after 3 and 5 years of risedronate, the ratio of pyridinium (non-reducible cross-link) to dehydrodihydroxylisinonorleucine (reducible cross-link), reflecting the maturation of collagenic matrix, was significantly lower compared with baseline (45).

Our study has some limitations. The comparisons were cross-sectional, with samples obtained from different studies, but all the measurements of variables were performed similarly. In $\mathrm{ALN}_{\mathrm{LT}}$ group, patients were treated from 3 to 10 years and this did not allow to conclude on the precise effect of the duration of the treatment. The fact that none of the variables of bone matrix quality correlated with the duration of treatment in the present study does not exclude such associations in shorter therapies $(<3$ years). Furthermore, we had limited data concerning the demographic profiles of our groups, and the long-term-treated group was composed of women recruited during medical consultations and few data concerning the compliance were available. However, the calculated reduction of Ac.F by up to $80 \%$ in cancellous bone was an argument for a good compliance to the medication as it was of the same magnitude of the decrease previously observed with a 3-year ALN treatment (46). MS/BS and BFR/BS were also significantly reduced. Furthermore, we had no information on the vitamin D status of the patients, which is a factor known to increase the DMB $(22,31)$. The fact that MAR was not different among the groups also validated our interpretation. The last limitation is the fact that the design of the study initially planed at tissue level did not permit to test the impact of the 
highlighted changes in whole bone strength. Among the patients of the treated group, no complications and no low-energy fractures were reported. This suggests that the decrease in hardness and crystallinity in most of the cases is insufficient to decrease whole bone strength.

To conclude, among PMOP women from outpatient clinics, a prolonged treatment with oral ALN maintained the DMB at a level higher than that in PMOP women, with no sign of hypermineralization despite markedly suppressed bone turnover. Long-term treatment was also associated with an increase in mineral maturity consistent with anti-resorptive effect, while both bone microhardness and bone mineral crystallinity were decreased. This could lead to a decrease in bone intrinsic quality. The study also suggests with caution that the decrease in local mechanical properties may not be specific to ALN or to the duration ( $>3$ years) of the treatment. Further studies need to be done to test these results in bone samples taken from patients who sustained femoral atypical fracture. Such an approach would help clarifying to what extent impairments in material and micromechanical properties may influence the whole bone resistance to fracture.

\section{Declaration of interest}

The authors declare that there is no conflict of interest that could be perceived as prejudicing the impartiality of the research reported.

\section{Funding}

This study was supported by the Institut National de la Santé et de la Recherche Médicale (INSERM) and a grant from Procter and Gamble.

\section{References}

1 Black DM, Cummings SR, Karpf DB, Cauley JA, Thompson DE, Nevitt MC, Bauer DC, Genant HK, Haskell WL, Marcus R, Ott SM, Torner JC, Quandt SA, Reiss TF \& Ensrud KE. Randomised trial of effect of alendronate on risk of fracture in women with existing vertebral fractures. Fracture Intervention Trial Research Group. Lancet 1996348 1535-1541. (doi:10.1016/S0140-6736(96) 07088-2)

2 McClung MR, Geusens P, Miller PD, Zippel H, Bensen WG, Roux C, Adami S, Fogelman I, Diamond T, Eastell R, Meunier PJ \& Reginster JY. Effect of risedronate on the risk of hip fracture in elderly women. Hip Intervention Program Study Group. New England Journal of Medicine 2001344 333-340. (doi:10.1056/ NEJM200102013440503)

3 Delmas PD \& Seeman E. Changes in bone mineral density explain little of the reduction in vertebral or nonvertebral fracture risk with anti-resorptive therapy. Bone 200434 599-604. (doi:10.1016/j.bone.2003.12.022)

4 Follet H, Boivin G, Rumelhart C \& Meunier PJ. The degree of mineralization is a determinant of bone strength: a study on human calcanei. Bone 200434 783-789. (doi:10.1016/j.bone. 2003.12.012)

5 Seeman E \& Delmas PD. Bone quality - the material and structural basis of bone strength and fragility. New England Journal of Medicine 2006354 2250-2261. (doi:10.1056/NEJMra053077)
6 Viguet-Carrin S, Garnero P \& Delmas PD. The role of collagen in bone strength. Osteoporosis International $2006 \quad 17$ 319-336. (doi:10.1007/s00198-005-2035-9)

7 Boivin GY, Chavassieux PM, Santora AC, Yates J \& Meunier PJ. Alendronate increases bone strength by increasing the mean degree of mineralization of bone tissue in osteoporotic women. Bone 2000 27 687-694. (doi:10.1016/S8756-3282(00)00376-8)

8 Boskey AL, Spevak L \& Weinstein RS. Spectroscopic markers of bone quality in alendronate-treated postmenopausal women. Osteoporosis International 200920 793-800. (doi:10.1007/ s00198-008-0725-9)

9 Roschger P, Rinnerthaler S, Yates J, Rodan GA, Fratzl P \& Klaushofer K. Alendronate increases degree and uniformity of mineralization in cancellous bone and decreases the porosity in cortical bone of osteoporotic women. Bone 200129 185-191. (doi:10.1016/S8756-3282(01)00485-9)

10 Borah B, Dufresne TE, Ritman EL, Jorgensen SM, Liu S, Chmielewski PA, Phipps RJ, Zhou X, Sibonga JD \& Turner RT. Long-term risedronate treatment normalizes mineralization and continues to preserve trabecular architecture: sequential triple biopsy studies with micro-computed tomography. Bone 200639 345-352. (doi:10.1016/j.bone.2006.01.161)

11 Allen MR, Iwata K, Phipps R \& Burr DB. Alterations in canine vertebral bone turnover, microdamage accumulation, and biomechanical properties following 1-year treatment with clinical treatment doses of risedronate or alendronate. Bone 200639 872-879. (doi:10.1016/j.bone.2006.04.028)

12 Mashiba T, Turner CH, Hirano T, Forwood MR, Johnston CC \& Burr DB. Effects of suppressed bone turnover by bisphosphonates on microdamage accumulation and biomechanical properties in clinically relevant skeletal sites in beagles. Bone $200128524-$ 531. (doi:10.1016/S8756-3282(01)00414-8)

13 Allen MR, Gineyts E, Leeming DJ, Burr DB \& Delmas PD. Bisphosphonates alter trabecular bone collagen cross-linking and isomerization in beagle dog vertebra. Osteoporosis International 200819 329-337. (doi:10.1007/s00198-007-0533-7)

14 Stepan JJ, Burr DB, Pavo I, Sipos A, Michalska D, Li J, Fahrleitner-Pammer A, Petto H, Westmore M, Michalsky D, Sato M \& Dobnig H. Low bone mineral density is associated with bone microdamage accumulation in postmenopausal women with osteoporosis. Bone 200741 378-385. (doi:10.1016/j.bone.2007. 04.198)

15 Giusti A, Hamdy NA \& Papapoulos SE. Atypical fractures of the femur and bisphosphonate therapy: a systematic review of case/case series studies. Bone 201047 169-180. (doi:10.1016/ j.bone.2010.05.019)

16 Visekruna M, Wilson D \& McKiernan FE. Severely suppressed bone turnover and atypical skeletal fragility. Journal of Clinical Endocrinology and Metabolism 200893 2948-2952. (doi:10. 1210/jc.2007-2803)

17 Odvina CV, Zerwekh JE, Rao DS, Maalouf N, Gottschalk FA \& Pak CY. Severely suppressed bone turnover: a potential complication of alendronate therapy. Journal of Clinical Endocrinology and Metabolism 200590 1294-1301. (doi:10.1210/jc.2004-0952)

18 Richer E, Lewis MA, Odvina CV, Vazquez MA, Smith BJ, Peterson RD, Poindexter JR, Antich PP \& Pak CY. Reduction in normalized bone elasticity following long-term bisphosphonate treatment as measured by ultrasound critical angle reflectometry. Osteoporosis International 200516 1384-1392. (doi:10.1007/ s00198-005-1848-x)

19 Woo SB, Hellstein JW \& Kalmar JR. Narrative review: bisphosphonates and osteonecrosis of the jaws. Annals of Internal Medicine 2006144 753-761.

20 Roschger P, Lombardi A, Misof BM, Maier G, Fratzl-Zelman N, Fratzl P \& Klaushofer K. Mineralization density distribution of postmenopausal osteoporotic bone is restored to normal after long-term alendronate treatment: qBEI and sSAXS data from the fracture intervention trial long-term extension (FLEX). Journal of Bone and Mineral Research 201025 48-55. (doi:10.1359/jbmr. 090702) 
21 Chapurlat RD, Arlot M, Burt-Pichat B, Chavassieux P, Roux JP, Portero-Muzy N \& Delmas PD. Microcrack frequency and bone remodeling in postmenopausal osteoporotic women on long-term bisphosphonates: a bone biopsy study. Journal of Bone and Mineral Research 200722 1502-1509. (doi:10.1359/jbmr.070609)

22 Boivin G, Lips P, Ott SM, Harper KD, Sarkar S, Pinette KV \& Meunier PJ. Contribution of raloxifene and calcium and vitamin D3 supplementation to the increase of the degree of mineralization of bone in postmenopausal women. Journal of Clinical Endocrinology and Metabolism 200388 4199-4205. (doi:10.1210/jc. 2002-022020)

23 Parfitt AM, Drezner MK, Glorieux FH, Kanis JA, Malluche H, Meunier PJ, Ott SM \& Recker RR. Bone histomorphometry: standardization of nomenclature, symbols, and units. Report of the ASBMR Histomorphometry Nomenclature Committee. Journal of Bone and Mineral Research 19872 595-610. (doi:10. 1002/jbmr.5650020617)

24 Boivin G, Bala Y, Doublier A, Farlay D, Ste-Marie LG, Meunier PJ \& Delmas PD. The role of mineralization and organic matrix in the microhardness of bone tissue from controls and osteoporotic patients. Bone 200843 532-538. (doi:10.1016/j.bone.2008.05.024)

25 Farlay D, Panczer G, Rey C, Delmas PD \& Boivin G. Mineral maturity and crystallinity index are distinct characteristics of bone mineral. Journal of Bone and Mineral Metabolism 201028 433-445. (doi:10.1007/s00774-009-0146-7)

26 Borah B, Ritman EL, Dufresne TE, Jorgensen SM, Liu S, Sacha J, Phipps RJ \& Turner RT. The effect of risedronate on bone mineralization as measured by micro-computed tomography with synchrotron radiation: correlation to histomorphometric indices of turnover. Bone 200537 1-9. (doi:10.1016/j.bone. 2005.03.017)

27 Black DM, Schwartz AV, Ensrud KE, Cauley JA, Levis S, Quandt SA, Satterfield S, Wallace RB, Bauer DC, Palermo L, Wehren LE, Lombardi A, Santora AC \& Cummings SR. Effects of continuing or stopping alendronate after 5 years of treatment: the Fracture Intervention Trial Long-term Extension (FLEX): a randomized trial. Journal of the American Medical Association 2006296 2927-2938. (doi:10.1001/jama.296.24.2927)

28 Bone HG, Hosking D, Devogelaer JP, Tucci JR, Emkey RD, Tonino RP, Rodriguez-Portales JA, Downs RW, Gupta J, Santora AC \& Liberman UA. Ten years' experience with alendronate for osteoporosis in postmenopausal women. New England Journal of Medicine 2004350 1189-1199. (doi:10.1056/NEJMoa030897)

29 Garnero P, Shih WJ, Gineyts E, Karpf DB \& Delmas PD. Comparison of new biochemical markers of bone turnover in late postmenopausal osteoporotic women in response to alendronate treatment. Journal of Clinical Endocrinology and Metabolism $1994 \mathbf{7 9}$ 1693-1700. (doi:10.1210/jc.79.6.1693)

30 Tucci JR, Tonino RP, Emkey RD, Peverly CA, Kher U \& Santora AC II. Effect of three years of oral alendronate treatment in postmenopausal women with osteoporosis. American Journal of Medicine 1996101 488-501. (doi:10.1016/S0002-9343(96)00282-3)

31 Fratzl P, Roschger P, Fratzl-Zelman N, Paschalis EP, Phipps R \& Klaushofer K. Evidence that treatment with risedronate in women with postmenopausal osteoporosis affects bone mineralization and bone volume. Calcified Tissue International $2007 \mathbf{8 1} 73-80$. (doi:10.1007/s00223-007-9039-8)

32 Boivin G \& Meunier PJ. The degree of mineralization of bone tissue measured by computerized quantitative contact microradiography. Calcified Tissue International 200270 503-511. (doi:10. 1007/s00223-001-2048-0)

33 Boivin G, Bala Y, Chapurlat R \& Delmas P. Long-term treatment with oral bisphosphonates in postmenopausal women: effects on the degree of mineralization and microhardness of bone. Journal of Bone and Mineral Research 200823 (Suppl 1) S10.
34 Brennan TC, Rizzoli R \& Ammann P. Selective modification of bone quality by PTH, pamidronate, or raloxifene. Journal of Bone and Mineral Research 200924 800-808. (doi:10.1359/jbmr. 081227)

35 Wang X, Shanbhag AS, Rubash HE \& Agrawal CM. Short-term effects of bisphosphonates on the biomechanical properties of canine bone. Journal of Biomedical Materials Research $19994 \mathbf{4 4}$ 456-460. (doi:10.1002/(SICI)1097-4636(19990315)44:4<45 6::AID-JBM12>3.0.CO;2-9)

36 Wang X, Allen MR, Burr DB, Lavernia EJ, Jeremic B \& Fyhrie DP. Identification of material parameters based on Mohr-Coulomb failure criterion for bisphosphonate treated canine vertebral cancellous bone. Bone $2008 \mathbf{4 3}$ 775-780. (doi:10.1016/j.bone. 2008.05.023)

37 Bala Y, Farlay D, Delmas PD, Meunier PJ \& Boivin G. Time sequence of secondary mineralization and microhardness in cortical and cancellous bone from ewes. Bone $2010 \mathbf{4 6}$ 1204-1212. (doi:10.1016/j.bone.2009.11.032)

38 Aydin HM, Hu B, Suso JS, El Haj A \& Yang Y. Study of tissue engineered bone nodules by Fourier transform infrared spectroscopy. Analyst 2011136 775-780. (doi:10.1039/c0an 00530d)

39 Gamsjaeger S, Buchinger B, Zwettler E, Recker R, Black D, Gasser JA, Eriksen EF, Klaushofer K \& Paschalis EP. Bone material properties in actively bone-forming trabeculae in postmenopausal women with osteoporosis after three years of treatment with onceyearly Zoledronic acid. Journal of Bone and Mineral Research 2011 26 12-18. (doi:10.1002/jbmr.180)

40 Russell RG, Watts NB, Ebetino FH \& Rogers MJ. Mechanisms of action of bisphosphonates: similarities and differences and their potential influence on clinical efficacy. Osteoporosis International 200819 733-759. (doi:10.1007/s00198-007-0540-8)

41 Ebetino FH, Barnett BL \& Russell RG. A computational model delineates differences in hydroxyapatite binding affinities of bisphosphonates in clinical use. Journal of Bone and Mineral Research 200520 (Suppl 1) S259.

42 Nancollas GH, Tang R, Phipps RJ, Henneman Z, Gulde S, Wu W, Mangood A, Russell RG \& Ebetino FH. Novel insights into actions of bisphosphonates on bone: differences in interactions with hydroxyapatite. Bone 200638 617-627. (doi:10.1016/j.bone. 2005.05.003)

43 Wu W, Gerard DE \& Nancollas GH. Nucleation at surfaces: the importance of interfacial energy. Journal of the American Society of Nephrology 199910 (Suppl 14) S355-S358.

44 Yerramshetty JS \& Akkus O. The associations between mineral crystallinity and the mechanical properties of human cortical bone. Bone 200842 476-482. (doi:10.1016/j.bone.2007.12. 001)

45 Durchschlag E, Paschalis EP, Zoehrer R, Roschger P, Fratzl P, Recker R, Phipps R \& Klaushofer K. Bone material properties in trabecular bone from human iliac crest biopsies after 3- and 5-year treatment with risedronate. Journal of Bone and Mineral Research 200621 1581-1590. (doi:10.1359/jbmr.060701)

46 Chavassieux PM, Arlot ME, Reda C, Wei L, Yates AJ \& Meunier PJ. Histomorphometric assessment of the long-term effects of alendronate on bone quality and remodeling in patients with osteoporosis. Journal of Clinical Investigation $1997 \mathbf{1 0 0}$ 1475-1480. (doi:10.1172/JCI119668)

Received 14 April 2011

Revised version received 18 July 2011

Accepted 5 August 2011 